\title{
Putting European lampreys into perspective: A global-scale multilocus phylogeny with a proposal for a generic structure of the Petromyzontidae
}

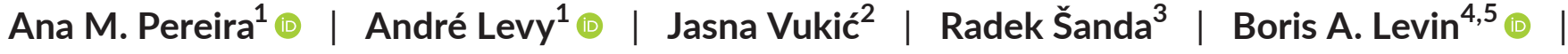 \\ Jörg Freyhof $^{6}$ | Matthias Geiger ${ }^{7}$ | Lukáš Choleva $^{8,9}$ | Sara M. Francisco ${ }^{1}$ ( ) | \\ Joana I. Robalo ${ }^{1}$
}

${ }^{1}$ MARE - Marine and Environmental Sciences Centre, ISPA - Instituto Universitário, Lisboa, Portugal

${ }^{2}$ Department of Ecology, Faculty of Science, Charles University in Prague, Prague, Czech Republic

${ }^{3}$ Department of Zoology, National Museum, Prague, Czech Republic

${ }^{4}$ Papanin Institute for Biology of Inland Waters, Russian Academy of Sciences, Borok, Russia

${ }^{5}$ Cherepovets State University, Cherepovets, Russia

${ }^{6}$ Museum für Naturkunde, Leibniz Institute for Evolution and Biodiversity Science, Berlin, Germany

${ }^{7}$ Zoologisches Forschungs Museum Alexander Koenig, Bonn, Germany

${ }^{8}$ Laboratory of Fish Genetics, Institute of Animal Physiology and Genetics CAS, Libechov, Czech Republic

${ }^{9}$ Department of Biology and Ecology, Faculty of Science, University of Ostrava, Ostrava, Czech Republic

\section{Correspondence}

Ana M. Pereira, MARE - Marine and Environmental Sciences Centre, ISPA - Instituto Universitário, Rua Jardim do Tabaco 34, 1149-041 Lisboa, Portugal. Email: ana_pereira@ispa.pt

Funding information

Ministry of Culture of the Czech Republic, Grant/Award Number: DKRVO 20192023/6.IV.c and 00023272; Ministry of Education, Youth, and Sports of the Czech Republic; SYNTHESYS, Grant/Award Number: CZ-TAF-3884; Fundação para a Ciência e a Tecnologia,

\begin{abstract}
Previous studies on the phylogenetic relationships between lamprey species relied either on a low number of morphological characters related to the feeding apparatus, or on a low number of molecular mitochondrial DNA markers. Here, we apply a multilocus approach to assess the phylogenetic relationships of northern hemisphere lampreys, with a special emphasis on the 17 European species. The study comprises two mitochondrial (cytochrome $c$ oxidase subunit 1 gene-DNA barcodes, and cytochrome $b$ gene) and two nuclear (internal transcribed spacers I and II) markers to investigate species' phylogenetic affinities. The phylogeny obtained with mitochondrial markers revealed a clear and highly supported separation of all northern hemisphere lampreys. Among those, our multilocus results show several polyphyletic genera, stressing the need for a taxonomic revision in a near future. Lampetra morii (Berg, 1931) from East Asia, often included in Eudontomyzon, is placed in the genus Lethenteron. Lampetra richardsoni Vladykov \& Follett, 1965 and Entosphenus hubbsi (Vladykov \& Kott, 1976) should be placed in a new genus, as well as the southern populations of Lethenteron camtschaticum (Tilesius, 1811) and Lethenteron reissneri (Dybowski, 1869). Considering European species, our results argue for a taxonomic revision of Eudontomyzon, with emphasis on Eudontomyzon vladykovi Oliva \& Zanandrea, 1959.
\end{abstract}

\section{KEYWORDS}

Europe, mitochondrial markers, nuclear markers, taxonomic revision

\section{Resumen}

Estudios anteriores sobre las relaciones filogenéticas entre especies de lampreas, se basan en un escaso número de caracteres morfológicos relacionados con las estructuras de alimentación, o en un bajo número de marcadores moleculares de ADN mitocondrial. Aquí aplicamos un enfoque multilocus para evaluar las relaciones filogenéticas de las lampreas del hemisferio norte, con especial énfasis en 17 especies

Contributing authors: André Levy (andre_levy@ispa.pt), Jasna Vukić (jvukic@seznam.cz), Radek Šanda (rsanda@seznam.cz), Boris A. Levin (borislyovin@mail.ru, borislyovin@gmail.com) Jörg Freyhof (joerg.freyhof@mfn.berlin), Matthias Geiger (m.geiger@leibniz-zfmk.de), Lukáš Choleva (Choleva@iapg.cas.cz), Sara M. Francisco (sara_francisco@ispa.pt), Joana I. Robalo (jrobalo@ispa.pt) 
Grant/Award Number: MARE/UIDB/ MAR/04292/2020; Russian Foundation for Basic Research, Grant/Award Number: 19-04-00719; Akademie Věd České Republiky, Grant/Award Number: 67985904; Russian Science Foundation, Grant/Award Number: 15-14-10020 europeas. Este estudio comprende dos marcadores mitocondriales (citocromo oxidasa c subunidad 1 -ADN barcodes, y citocromo oxidasa b) y dos marcadores nucleares (espaciadores transcritos internos I y II (ITS) ) para investigar la afinidad filogenética de las especies. La filogenia obtenida con losmarcadores mitocondriales reveló una separación clara y altamente apoyada de todas las lampreas del hemisferio norte. Entre ellas, nuestros resultados multilocus muestran varios géneros polifiléticos, lo que resalta la necesidad de una revisión taxonómica en el futuro. Lampetra morii (Berg, 1931) de Asia oriental, a menudo incluida en Eudontomyzon, se sitúa en el género Lethenteron. Lampetra richardsoni Vladykov \& Follett, 1965 y Entosphenus hubbsi (Vladykov \& Kott, 1976) deben colocarse en un nuevo género, así como las poblaciones meridionales de Lethenteron camtschaticum (Tilesius, 1811) y Lethenteron reissneri (Dybowski, 1869). Considerando las especies europeas, nuestros resultados abogan por una revisión taxonómica de Eudontomyzon, con énfasis en Eudontomyzon vladykovi Oliva \& Zanandrea, 1959.

\section{1 | INTRODUCTION}

Lampreys are an ancient vertebrate group, with a general anatomy conserved for at least 360 million years (Gess et al., 2006). This group's life cycle includes a filter feeding larval phase that lasts for several years, while buried in freshwater sediment (e.g., Potter et al., 2015; Renaud, 2011). After this growth period, metamorphosis takes place and individuals acquire teeth on the oral disk, functional eyes and, in certain species, osmoregulatory ability, allowing them to enter marine waters. In some species, juveniles migrate to the sea or to a different freshwater body, and a trophic phase begins. The animals then feed by parasitism or predation for some time, while growing and sexually maturing. After this period, they migrate back to the rivers, where they spawn and end their semelparous life (e.g., Potter et al., 2015; Renaud, 2011). This life cycle is usually considered the ancestral state in lampreys (Docker, 2009). Other lampreys lack a trophic phase and spawning follows metamorphosis in the freshwater body where larval growth took place. These species are called non-trophic and, together with their ancestral trophic species, form species pairs or species complexes. Several genera include one trophic and one or several non-trophic species. In this situation, the non-trophic species are called satellite species (Vladykov, \& Kott, 1979). When the non-trophic satellite species evolved recently, one expects a similar morphology between trophic and non-trophic species. This phenomenon has been observed in many lamprey genera (Potter et al., 2015). However, when divergence is old, the non-trophic species may present a morphology quite distinct from the ancestor, as the non-functional feeding apparatus could have degenerated (Docker, 2009). Therefore, traditional morphology-based phylogenetic analyses have only considered the relationships between trophic species, assuming these as proxies for their respective satellite ones (Gill et al., 2003).

Lampreys occupy wide geographic areas, displaying an anti-tropical distribution (Renaud, 2011). They are currently restricted to the regions above $20^{\circ}$ northern and southern latitudes (Renaud, 2011). In the southern hemisphere, there are two families of lampreys: Geotriidae, with two predatory species (Riva-Rossi et al., 2020); and Mordaciidae, with three species, two of which are trophic. In the northern hemisphere, the family Petromyzontidae contains approximately 40 species, 15 of which with a trophic life cycle (Potter et al., 2015).

A morphology-based phylogeny of trophic lamprey species was published by Gill et al. (2003) using several characters: mouth structure, number and type of teeth and oral laminas, number and shape of velar tentacles, eye position, relative position of dorsal fins, and position of the cloaca relative to the dorsal fins. This work revealed a basal polytomy, failing to resolve the relationship between the families Geotriidae, Mordaciidae, and Petromyzontidae (Figure 1 left). The latter was shown to be monophyletic and its basal dichotomy revealed two sister groups, one grouping Ichthyomyzon and Petromyzon (both North American genera, but the anadromous Petromyzon also occurs in Europe) and the other one clustering the remaining northern hemisphere lamprey species. In the latter group, the most basal genus was Caspiomyzon (confined to the Caspian Sea), followed by Tetrapleurodon (a Mexican Pacific genus) and Entosphenus (a Pacific genus, present in both, North America and Asia). The remaining species belong to three distinct genera: Lampetra (a West Palearctic and North American genus), its sister genus Eudontomyzon (European with one Asian species), and Lethenteron (Europe, Arctic, and Asia).

The phylogenetic relationships between the aforementioned trophic species were also assessed in molecular studies. Using the mitochondrial cytochrome $b$ gene, Potter et al. (2015) revealed a somewhat different topology: the basal polytomy was resolved, with Mordaciidae as the most ancient family and sister to the Geotriidae + Petromyzontidae group (Figure 1 right); contrasting results were also found for within the group Lethenteron + Eudontomyzo $n+$ Lampetra, with the cytb phylogeny raising questions about the taxonomic validity/congruence of the genus Eudontomyzon and Lampetra.

The contrasting tree topologies obtained with morphological and molecular data may be related to methodological limitations. 
FIGURE 1 Relationships between trophic lamprey species using morphological characters (on the left) and genetic data (on the right), after Potter et al. (2015)

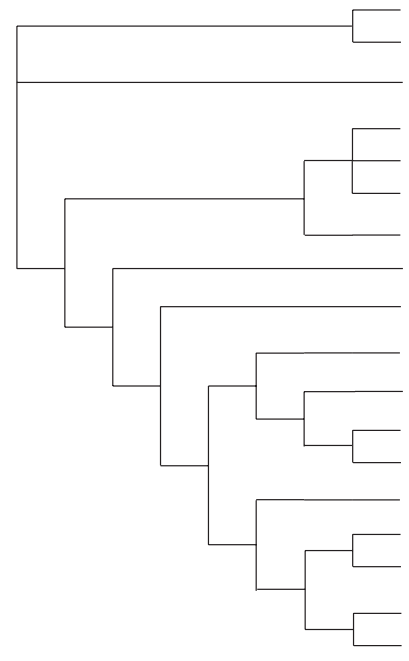

Mordacia mordax Mordacia lapicida Geotria australis Ichthyomyzon bdellium Ichthyomyzon castaneus Ichthyomyzon unicuspis Petromyzon marinus Caspiomyzon wagneri Tetrapleurodon Entosphenus minimus Entosphenus similis Entosphenus macrostomus Entosphenus tridentatus Lethenteron camtschaticum Eudontomyzon morii Endontomyzon danfordi Lampetra fluviatilis Lampetra ayresii

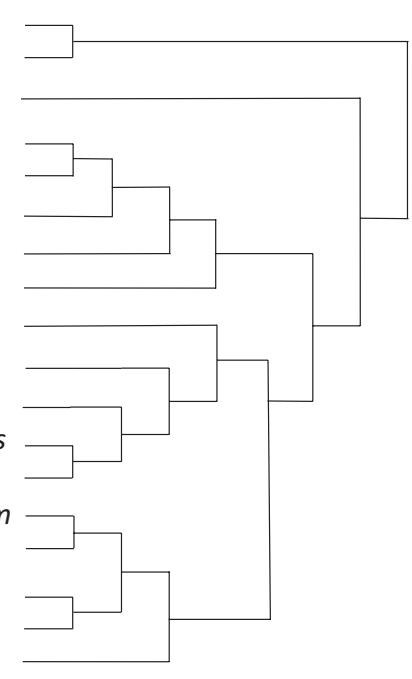

Morphological studies rely on few characters, mostly associated with the feeding apparatus (Docker et al., 1999), likely to reflect homoplasy. Lampreys are thus still a challenge for taxonomists and a good example for cryptic taxa exhibiting only few characters that can be measured or counted (no fin rays, no scales, and no ossified structures). Furthermore, lampreys show strong allometric growth after metamorphosis (Krappe, 2004) limiting morphometric studies to individuals in exactly the same phase of life. Krappe (2004) reports growth of the disk and shrinkage of the body and tail between 5\%-15\% after metamorphosis for different body proportions in Lampetra planeri . Therefore, the traditional taxonomy in lampreys is mainly based on their dentition and number of myomeres. On the other hand, molecular studies conducted so far used only mitochondrial genes (Potter et al., 2015). Hence, a comprehensive study with a broad database, including non-trophic species and additional molecular markers (with both nuclear and mitochondrial genes), is still lacking, despite its relevance in clarifying the phylogenetic relationships among the different families of lampreys.

Here, we apply a multilocus approach to assess the phylogenetic relationships of northern hemisphere lampreys, with a special emphasis on European species. This study comprises mitochondrial marker sequences (cytochrome c oxidase subunit 1 gene [COI]-DNA barcodes, and cytochrome $b$ gene [cytb]) and nuclear markers (internal transcribed spacers I and II [ITS-1 and ITS-2]), the spacer DNA regions situated between the nuclear ribosomal RNA genes. A total of 17 European species were investigated. This is the first work to include mitochondrial and nuclear markers in a wide number of lamprey species with trophic and non-trophic lifecycles, shedding light into taxonomical/genetic discordances found in previous studies and providing insight into a fully comprehensive phylogeny of the group.

\section{2 | MATERIALS AND METHODS}

DNA sequences were obtained from 37 individuals from 17 described and one putative undescribed European species (Barbieri et al., 2015) (Table 1). Lampreys were caught by electrofishing or collected by hand net following local laws and regulations. Specimens, mainly larvae, were attributed to each species based on their sampling location and preserved in ethanol $96^{\circ}$ for molecular analyses. Whenever possible, samples were taken from individuals near the species-type locality. Given the diversity of type localities attributed to Eudontomyzon vladykovi, individuals from two sampling points were included in this study. Two samples of the Mexican Tetrapleurodon geminis, were also included for topological stability. Sample tissue was deposited in ISPA-IU Genetics laboratory.

Total DNA was obtained using REDExtract-N-Amp kit (SigmaAldrich) following the manufacturer's instructions. Amplifications were conducted in $20 \mu \mathrm{l}$ total-reaction volume with $10 \mu \mathrm{l}$ of REDExtract-N-ampl PCR reaction mix (Sigma-Aldrich), $0.8 \mu$ l of each primer $(10 \mu \mathrm{M}), 4.4 \mu \mathrm{l}$ of sigma-water, and $4 \mu \mathrm{l}$ of template DNA. COI was amplified using the primers COI-F1(5'-TCA ACC ACC CAC AAA GAC ATT GGC AC-3' (Ivanova et al., 2007) and COI-2R (5'ACT TCA GGG TGA CCG AAG AAT CAG AA-3'; adapted from Ward et al., 2005). The amplicon size was 698 bp (alignment size 604 bp). Cyt $b$ was amplified using the primers Cytb494L ( $3^{\prime}$-AGC CTT CTC TTC AGT TAT ACA CAT TTG TCG-3') and Phe1612H (5'-CTT CAG TGC TCT GCT TTA ATG-3') (Lang et al., 2009). The amplicon size was $1187 \mathrm{bp}$ (alignment size 894 bp). ITS-1 was amplified using the primers Kp2 (5'-AAA AAG CTT CCG TAG GTG AAC CTG CG-3') and 5.8S (5'-AGC TTG CTG CGT TCT TCA TCG A-3'; Phillips et al., 1995). The amplicon size was 433 bp (alignment size 340 bp). ITS-2 was amplified using the primers 5.8SR (5'-CTA CGC CTG TCT GAG TGT C-3') and 28S (5'-ATA TGC TTA AAT TCA GCG GG-3') (Phillips et al., 1995). The amplicon size was 393 bp (alignment size 293 bp). PCR followed usual conditions, with $55^{\circ} \mathrm{C}$ as annealing temperature for all fragments. Sequencing and purification were performed in Macrogen Europe.

Chromatograms were inspected and edited using CodonCode Aligner (CodonCode Corporation, www.codoncode.com). GenBank accession numbers of obtained sequences (from MW917204 to MW917227, MW925712 to MW925743, MW937280 to MW937308, and MW937309 to MW937342) are listed in Table 1 and alignments presented in supplementary material. 
TA B LE 1 Lamprey species (trophic species in red, non-trophic species in black), distributions ( ${ }^{\text {EUR }}$-Europe; ${ }^{\text {ENA }}$-Eastern North America; WNA_Western North America; ${ }^{\text {AS }}$-Asia; ${ }^{\text {AUS }}$-Australia; ${ }^{\text {SA }}$-South America), specimen vouchers and GenBank accession numbers of samples used in this study (accession numbers marked with ${ }^{\text {gb }}$ are available GenBank sequences)

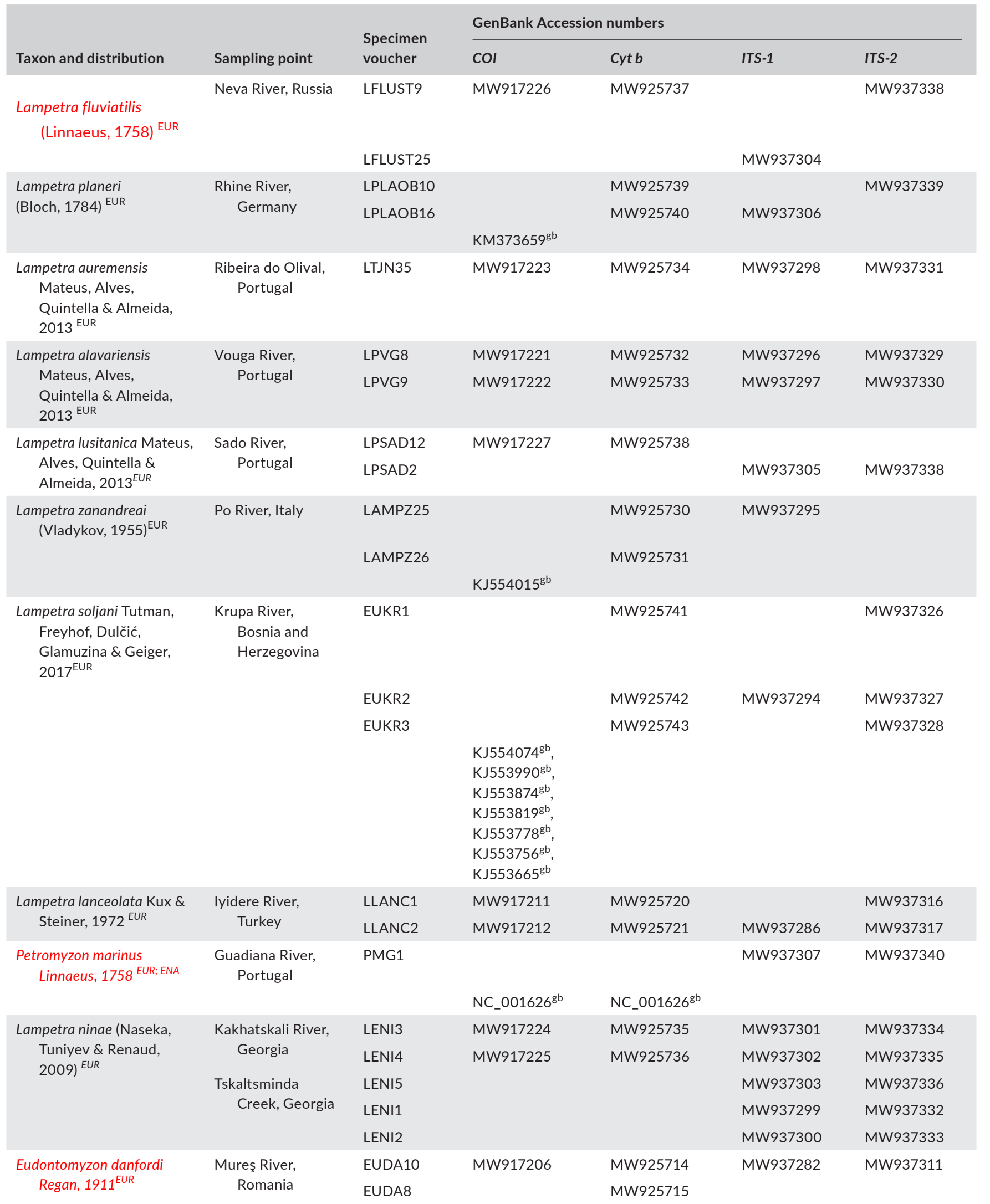


TABLE 1 (Continued)

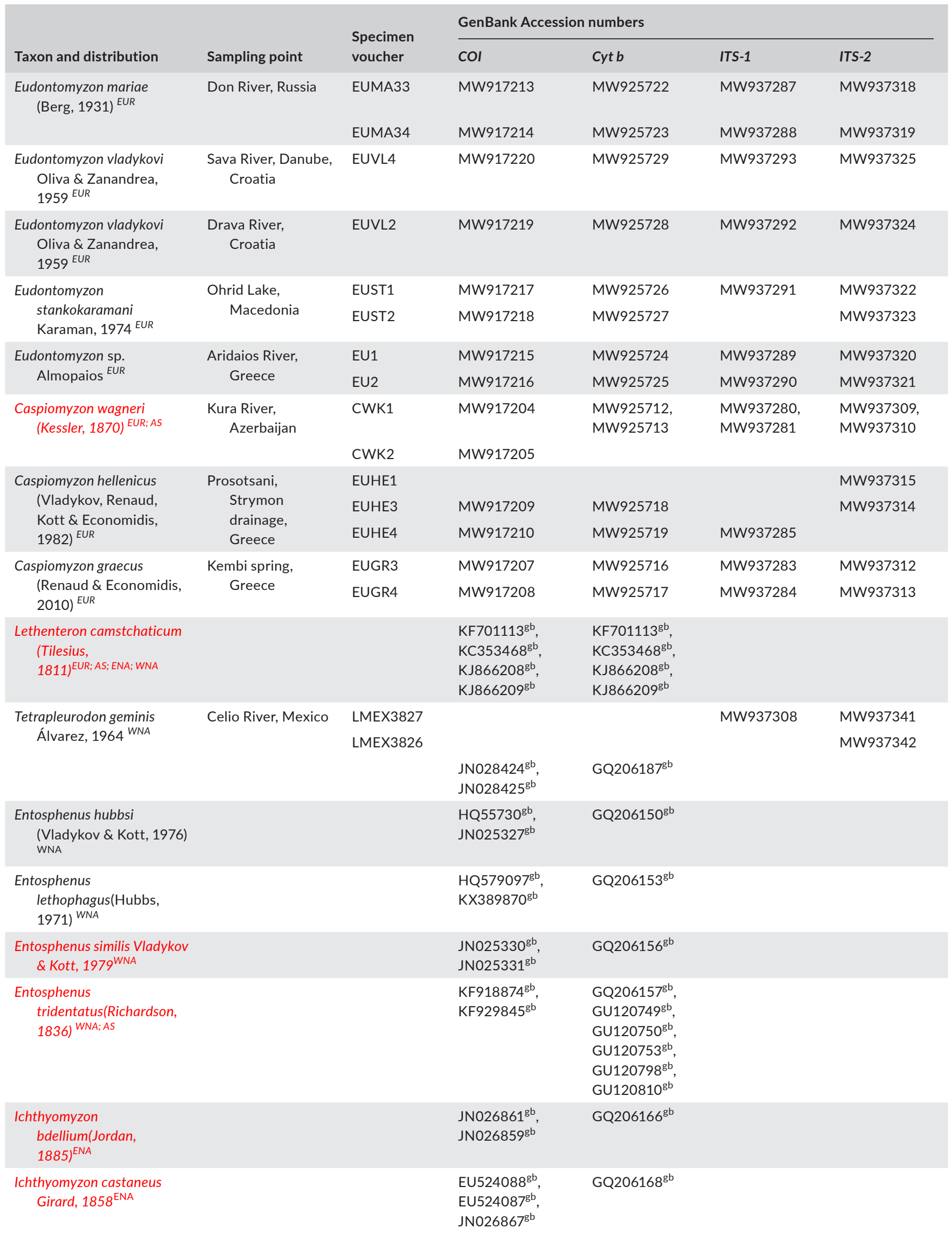


TABLE 1 (Continued)

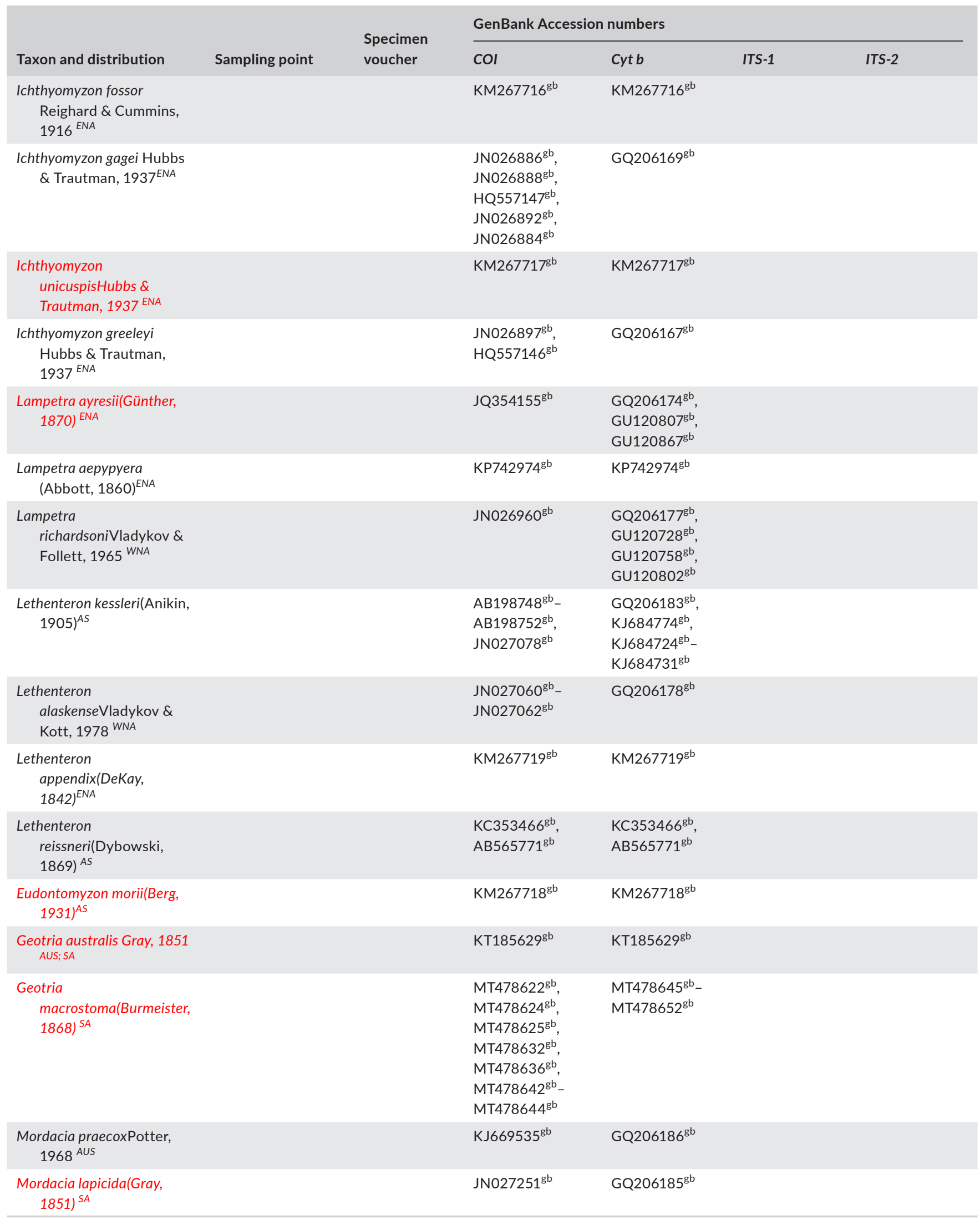


Whenever published sequences were available, they were added to the dataset and used in the analyses (Table 1-a total of $65 \mathrm{COI}$ sequences available from 28 species and 55 cyt $b$ sequences available from 25 species).

The mitochondrial database was extended by including $c y t b$ and $\mathrm{COI}$ sequences for 23 additional taxa available in GenBank: Entosphenus hubbsi, Entosphenus lethophagus, Entosphenus similis, Entosphenus tridentatus, Eudontomyzon morii, Geotria australis, Geotria macrostoma, Ichthyomyzon bdellium, Ichthyomyzon castanaeus, Ichthyomyzon fossor, Ichthyomyzon gagei, Ichthyomyzon unicuspis, Ichthyomyzon greeleyi, Lampetra ayresii, Lampetra aepypyera, Lampetra richardsoni, Lethenteron camtschaticum, Lethenteron kessleri, Lethenteron alaskense, Lethenteron appendix, Lethenteron reissneri, Mordacia praecox, and Mordacia lapicida ( see Table 1 for details). Sequences were selected using the following criteria: when mitogenomes were available, their cytb and $\mathrm{COI}$ were selected from the same individual; when mitogenomes were not available, only longer sequences ( $>500 \mathrm{bp}$ ) were used; when several longer sequences were available, all haplotypes were used; sequences with ambiguities were discarded whenever other sequences were available. We concatenated sequences from the same individual, whenever possible.

Maximum Composite Likelihood genetic distances between sequences and net distances between taxa were estimated using Mega v.7 (Kumar et al., 2016). Phylogenetic analyses were performed on all markers independently (see Alignments S1-S3 for European species and S4 and S5 for all lamprey species), on a mitochondrial alignment (concatenating cytb and COI-see alignments S6 for European species and S7 for all lamprey species), and on a full concatenation of all markers (Alignment S8 for European species). Given their physical proximity, ITS-1 and ITS-2 were considered a single marker. Maximum parsimony-based (MP) phylogenetic relationships were estimated using PAUP (Swofford, 2001), with 100 heuristic searches using random additions of sequences and implementing the TBR algorithm. Branch support values for each node were tested by bootstrap analysis, with 1000 resamplings (Felsenstein, 1985). Maximum likelihood (ML) phylogenetic trees were inferred using RAxML BlackBox (Stamatakis et al., 2008). Branch support was tested by 100 rapid bootstrap inferences. Bayesian analysis (BA) was performed using MrBayes 3.2.6 (Ronquist et al., 2012) with two independent runs of four simultaneous Markov Monte Carlo chains (MCMC) for four million generations (sampling every 100 generations). Separate partitions were used for each mitochondrial protein-coding gene, while also partitioning the first and second codon positions from third codon positions, each with independent GTR models.

In addition, we also estimated the phylogeny of European species and their divergence times using BEAST v. 1.8.4 (Drummond et al., 2012), with two separate site and clock models, one for both mitochondrial and another for both nuclear markers. A lognormal relaxed clock was assumed for both regions. We applied an a priori rate of 0.01 substitutions/site/MY for the mitochondrial markers, as previously used for lampreys by Docker et al. (1999) and consistent with Kuraku and Kuratani (2006), while clock rates for the nuclear markers were left with a uniform prior, due to the lack of any suitable rate estimate. We used a Yule speciation prior for both partitions and ran four independent analyses for one billion generations, logging parameters every 10,000 generations. We used a burn-in of $10 \%$, combined the four analyses using LogCombiner v.1.10.4. (Drummond et al., 2012), and checked for convergence of all parameters by inspecting Effective Sample Size (ESS) values, using Tracer v.1.7.2. Convergence was considered acceptable when ESS values were $>300$. The maximum clade credibility tree was constructed with TreeAnnotator v.1.10.4 (Drummond et al., 2012).

\section{3 | RESULTS}

The phylogeny obtained using the mitochondrial dataset (895 bp $c y t b+604$ bp COI) revealed a clear separation of northern hemisphere lampreys from southern ones with high support (Figure 2 and Figures S1 and S2). Northern hemisphere lampreys formed two basal clades. The first comprised Caspiomyzon wagneri and its two Greek satellite species, Caspiomyzon graecus and Caspiomyzon hellenicus, together with their sister group Petromyzon + Ichthyomyzon (T clade in Figure 2). In the second basal clade, neither Lethenteron, Lampetra nor Eudontomyzon were found to be monophyletic. The representatives of the genus Lethenteron appeared in two subclades (clades $U$ and $\mathrm{V}$ in Figure 2), and the species Le. camtschaticum in both: one clustering most of the species of this genus ( $V$ clade in Figure 2 ) and a second in a basal position ( $U$ clade in Figure 2). The representatives of the genus Lampetra appeared in four clades, one of them comprising all European Lampetra species ( $Z$ clade in Figure 2). Lampetra richardsoni and La. ayresii and La. aepytera were excluded from this clade and recovered as basal to subclades comprising the majority of Eudontomyzon and Lampetra species. All Eudontomyzon species clustered in a monophyletic group $X$ clade in Figure 2, except Eu. morii, which clusters with Lethenteron and Lampetra of the $\checkmark$ clade in Figure 2.

The phylogenetic relationships among European lamprey species inferred with the concatenated dataset (2151 bp long, from COI, cytb, ITS-1, and ITS-2) also recovered well-supported subclades for Eudontomyzon and Lampetra (Figure 3). In contrast, C. graecus and C. hellenicus did not cluster with $C$. wagneri, and Petromyzon marinus had a different position from the mitochondrial-based tree (cf. Figures 2 and 3).

Within Lampetra clade, the different analyses yielded a wellsupported subclade including Lampetra zanandreai, Lampetra lanceolata, Lampetra soljani, and Lampetra ninae. This subclade is grouped with the other European Lampetra, when using both the complete and the mitochondrial datasets (Figures 2 and 3), but not with the concatenated nuclear markers alone (Figures S3-S5). The genetic distances between these clades are presented in Table 2 .

According to the calibrated species tree (Figure 4), Eudontomyzon and Lampetra separated from each other around three mya. The group comprising $P$. marinus, $C$. wagneri, and $C$. graecus and $C$. hellenicus separated from the rest of analyzed species around 16 mya. 


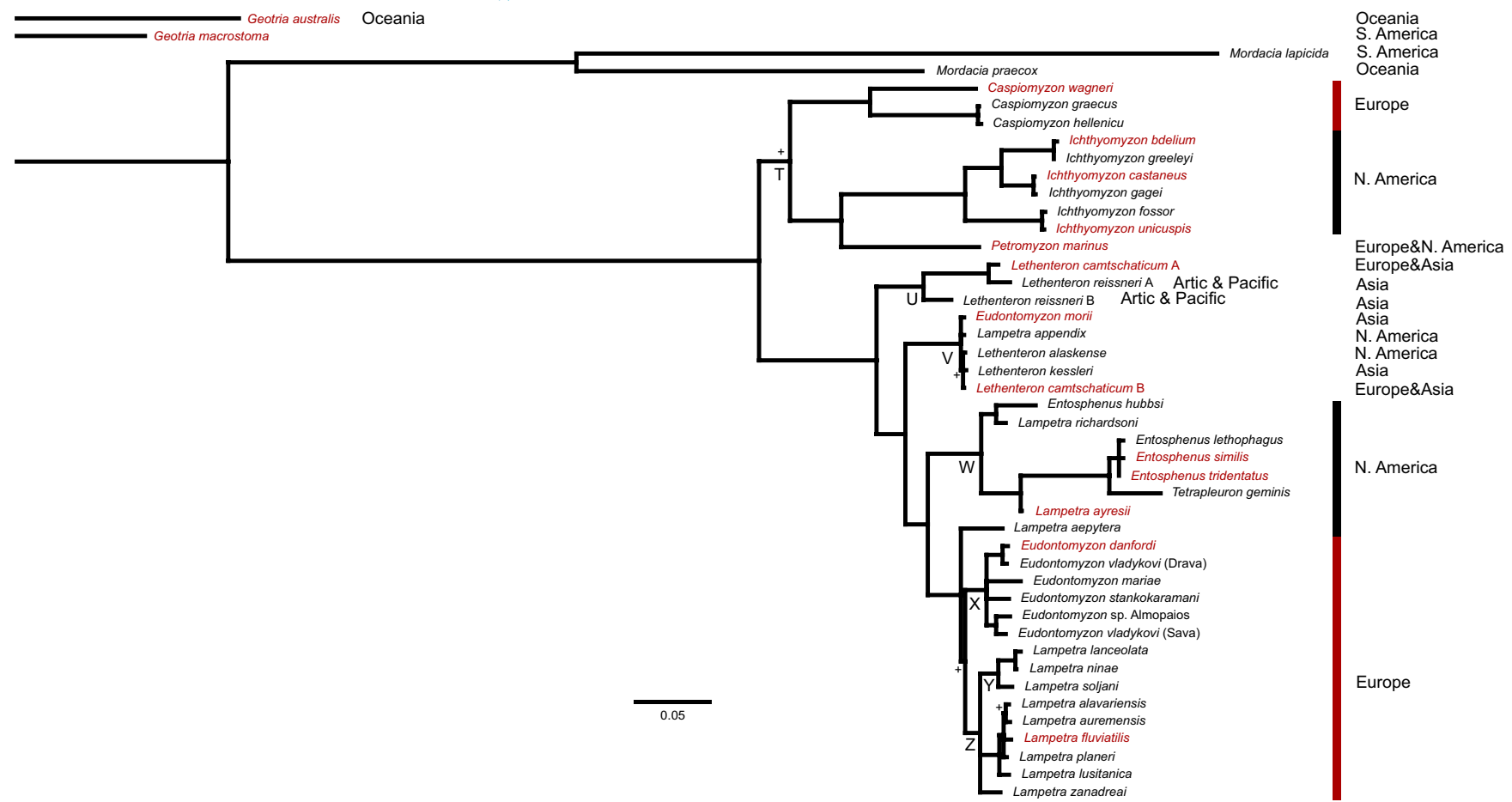

FIGURE 2 Bayesian analysis (BA) phylogenetic tree based calculated with concatenated COI and cytb markers from all lampreys included in this study, estimated using Mr. Bayes. All depicted bifurcating nodes had a posterior probability $>0.99$, except nodes with symbol $(0.75<+<0.90)$. Scale bar indicates nucleotide substitutions per site. Trophic species are indicated in red. Letters T-Z indicate clades referred to in the text

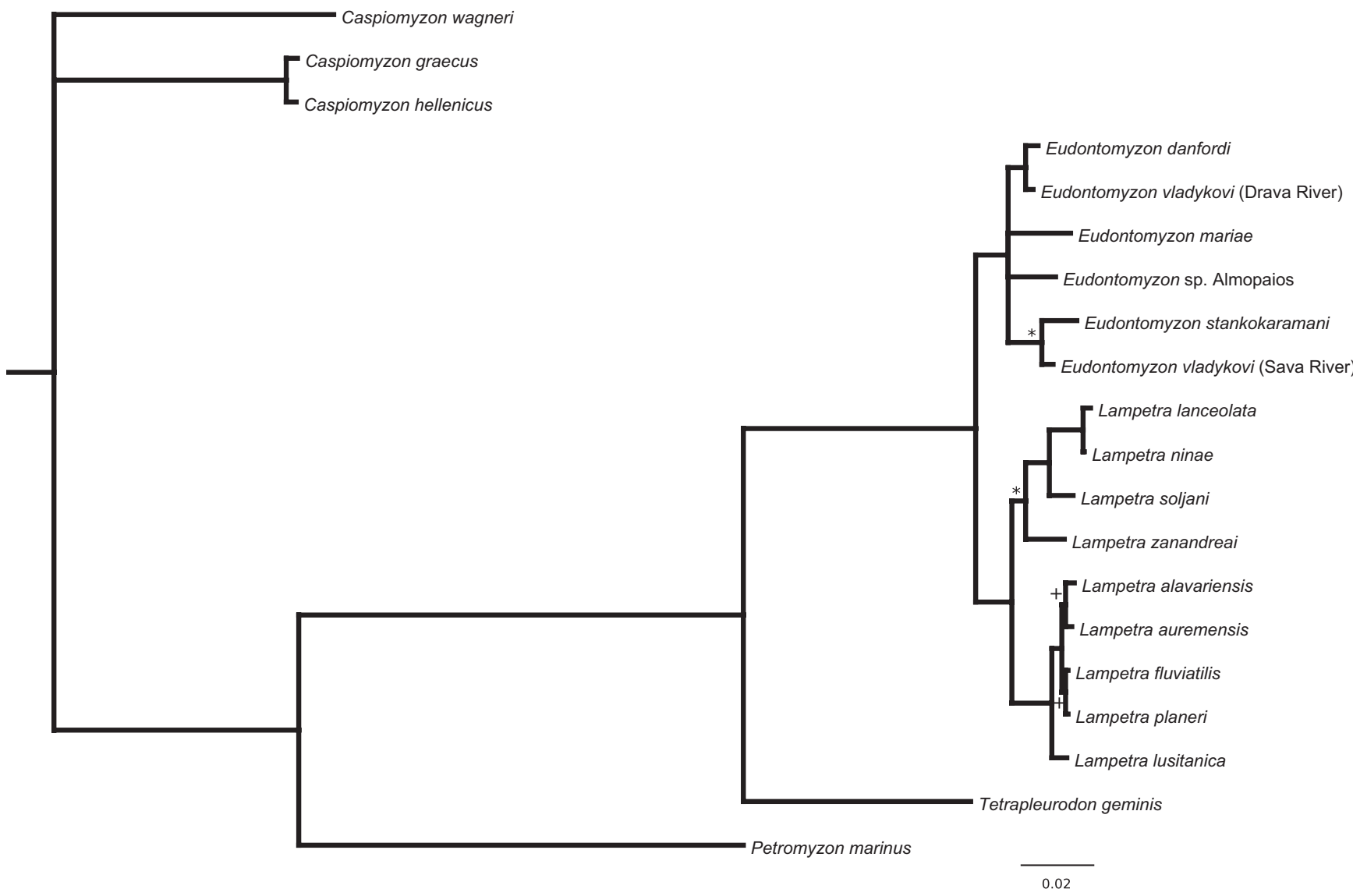

FIGURE 3 Maximum credibility species tree obtained using *BEAST, based on two underlying genealogies: mitochondrial markers (COI and $c y t b$ ) and nuclear markers (ITS-1 and ITS-2, considered as a single linked marker given the physical proximity of both regions). All nodes have a posterior probability $>0.99$, except nodes with symbol $\left(0.90<{ }^{*}<0.99 ; 0.75<+<0.90\right)$ 
TABLE 2 Average Maximum Composite Likelihood estimates of molecular distance $(\% \pm S E)$ within and between major European lamprey clades, using the COI, cytb, ITS-1, and ITS-2 fragments, respectively

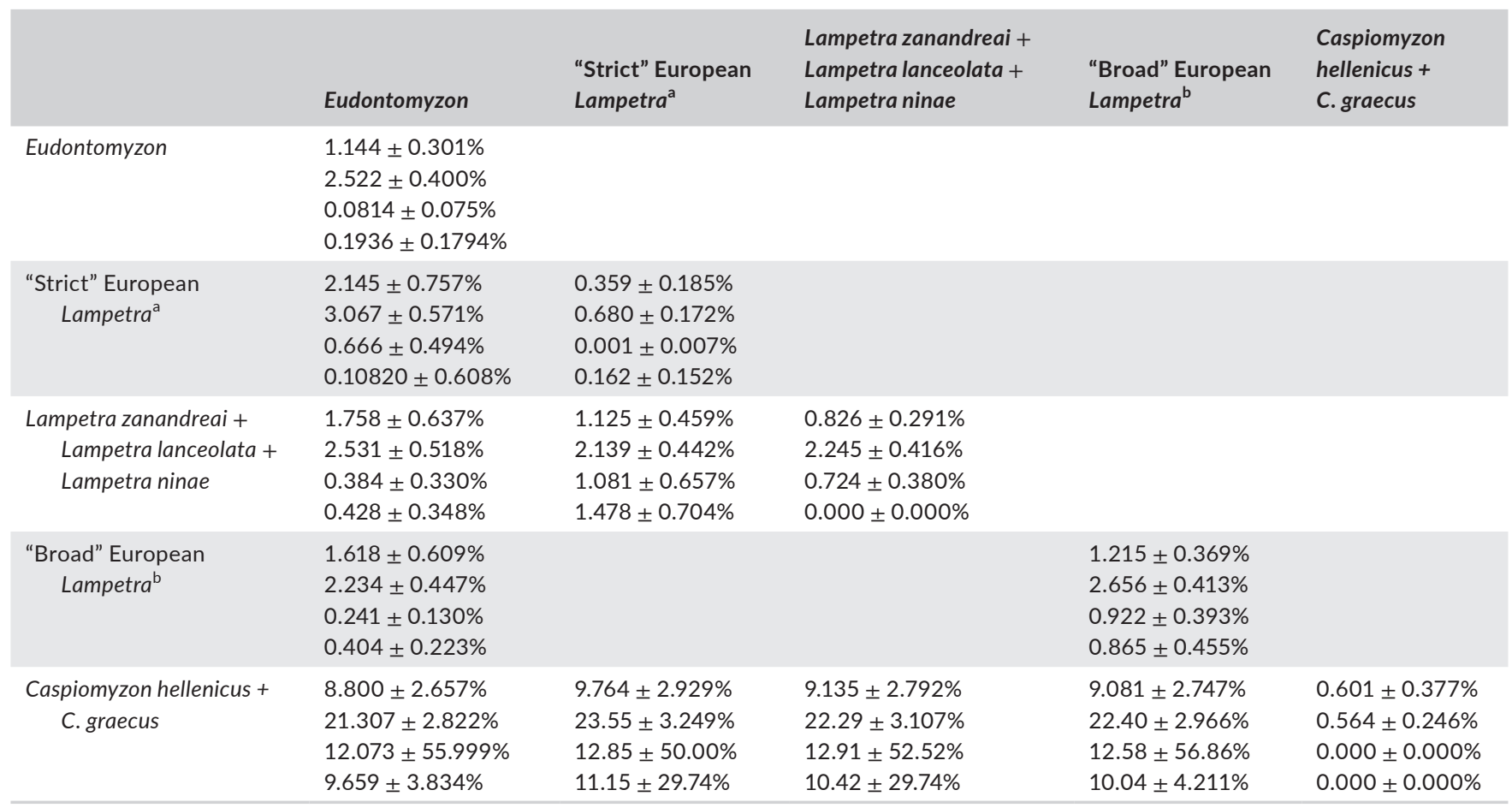

Estimates were calculated using Mega v.7. The "strict" European Lampetra clade includes Lampetra fluviatilis, Lampetra planeri, Lampetra alavariensis, Lampetra auremensis, and Lampetra lusitanica. The "broad" European Lampetra clade also includes Lampetra zanandreai, Lampetra lanceolata, and Lampetra ninae.

${ }^{a}$ Includes La. fluviatilis, La. planeri, La. alavariensis, La. auremensis, and La. Iusitanica.

${ }^{b}$ Includes La. fluviatilis, La. planeri, La. alavariensis, La. auremensis, La. Iusitanica, La. zanandreai, La. lanceolata, and La. ninae.

Separation of C. graecus and C. hellenicus from C. wagneri took place around 7 mya (Figure 4, Table S1). The mean estimated ITS clock was 0.0034 substitutions/site/MY (95\% HPD interval of $2.22 \times 10^{-3}$ to $4.73 \times 10^{-3}$ ).

\section{4 | DISCUSSION}

\section{1 | Inferences from the mitochondrial dataset}

In this comprehensive lamprey phylogenetic study, the monophyly of northern hemisphere lampreys is clearly confirmed (Figure 2). One of our most striking results was the polyphyletic nature of four northern hemisphere genera of lampreys, resulting in the need for future taxonomic revision of Lethenteron, Entosphenus, Lampetra, and Eudontomyzon. The general topology of the phylogenetic tree resulting from the concatenated mitochondrial data is similar to that found by Lang et al. (2009) and Potter at al. (2015) using only the cytb gene. This was expected, as we used the same or similar sequences as used in those studies. Nevertheless, the inclusion of mitochondrial $\mathrm{COI}$ data provided better support for their conclusions and some differences concerning genus relationships.

The genus Lethenteron appeared in two well-separated clades. Lethenteron camtschaticum was polyphyletic when using the concatenated mitochondrial dataset (Figure 2). Considering that the type locality of this genus-type species (Le. appendix) is in USA, we argue that the taxa in clade $\mathrm{V}$ (northern populations of Le. camtschaticum, Le. appendix, Le. alaskense, Le. kessleri and "Eu." morii) should be considered Lethenteron, while the southern populations of Le. camtschaticum and Le. reissneri (clade $U$ ) should be assigned to a new genus. In the work of Lang et al. (2009), Le. reissneri was shown to belong to Lethenteron. However, the samples included in that study were from the northern area of distribution of the species (in Russia), while those in our study (taken from complete mitochondrial genomes) are from the southern area (Japan). Lang et al. (2009) also included two undescribed Lethenteron: Le. sp. N, collected in Japan, grouped with other Lethenteron species; and Le. sp. S, sampled in South Korea, shown to belong to a new undescribed genus. The phylogenetic position of this new genus is similar to what was found in the present study for Le. camtschaticum and Le. reissneri, both from Japan. Both studies strongly suggest that Lethenteron is a northern genus, comprising species from Eastern and Western North America basins, Artic basins, and northwest Pacific drainages (including "Eu." morii, which is here proposed to be a species of Lethenteron). Conversely, a new genus should be described to include southern Japan and South Korea lampreys.

Our mitochondrial results also revealed the polyphyletic nature of the genus Entosphenus: a clade comprising the type species 


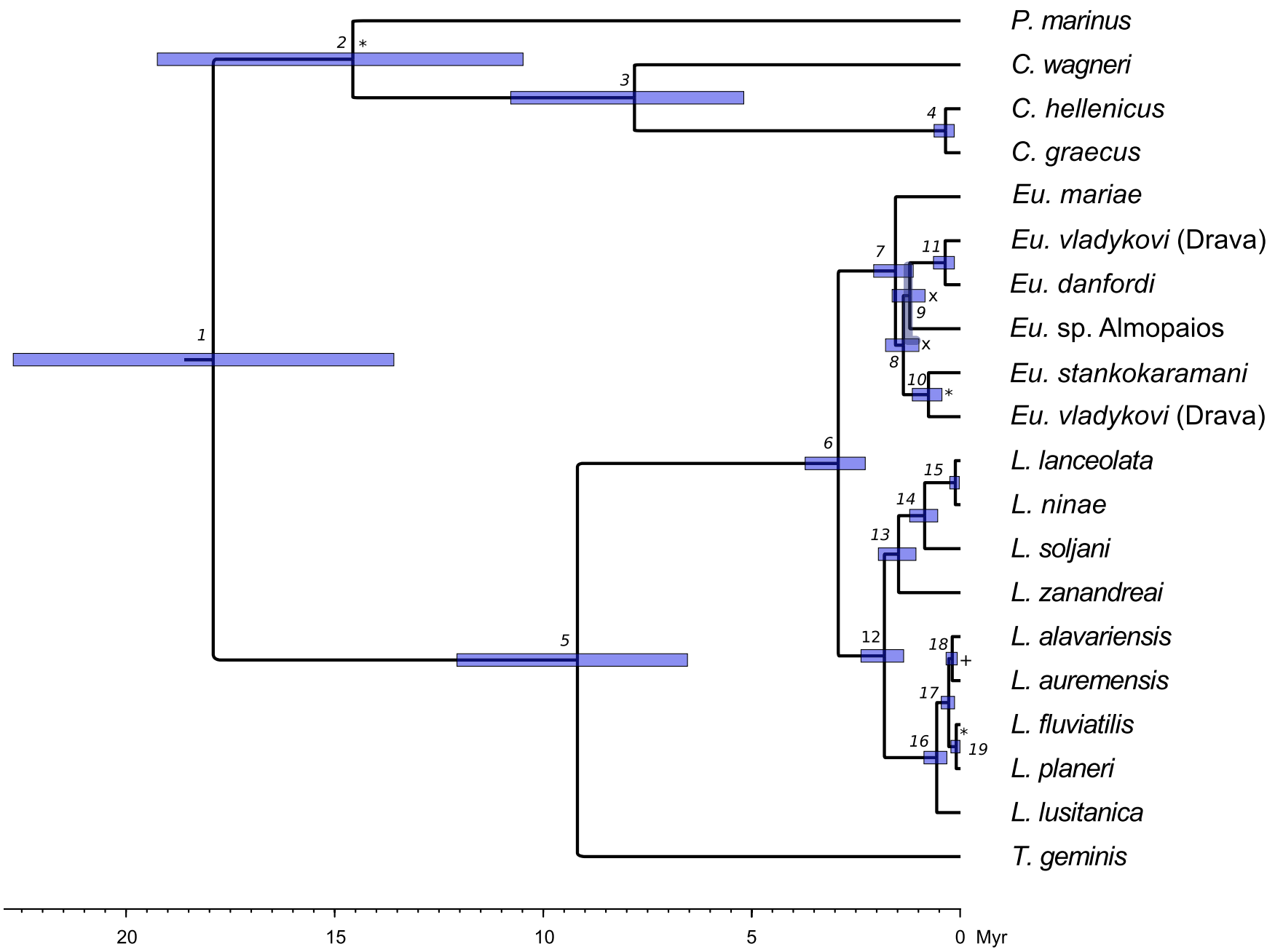

FIGURE 4 BA tree with time-calibrated maximum clade credibility from BEAST analysis, calculated with mitochondrial (COI and cytb) and nuclear (ITS-1 and ITS-2) data. Node bars depict 95\% highest posterior density. All nodes have a posterior probability $>0.99$, except nodes with symbol $\left(0.90<{ }^{*}<0.99 ; 0.8<+<0.9 ; 0.7<\times<0.8\right)$. Node age and HPD 95\% range for each numbered node is indicated in Table S1

En. tridentatus, En. lethophagus, and En. similis, and another clade, clustering En. hubbsi and La. richardsoni. These phylogenetic relationships had already been suggested by Lang et al. (2009) using only cytb. However, the two studies yielded distinct results concerning La. ayresii: in Lang et al. (2009), this species is sister to La. richardsoni, while in the present work, it is closer to the genus Entosphenus than to the La. richardsoni and En. hubbsi clade. Therefore, we suggest the description of a new genus encompassing En. hubbsi and La. richardsoni. The taxonomic clarification of La. ayresii requires further work using nuclear markers and / or genomic data. For the time being, we exclude La. richardsoni and also La. ayresii from Lampetra and encourage the description of a new genus for these species.

The present work corroborated additional conclusions of previous studies such as the suggestion of Lang et al. (2009) to only include the European species in the genus Lampetra, moving Lampetra richarsoni, La. ayresii, and Lampetra aepyptera to new genera. This later species, although close to European Lampetra, was already considered Okelbergia aepyptera by Lang et al. (2009).

\subsection{Inferences from the extended dataset (mitochondrial + nuclear markers)}

Concerning the West Paleartic species, the present phylogenetic analysis with the extended dataset revealed the monophyly of Eudontomyzon and Lampetra, clustering them as sister genera (Figure 3). A similar result was reported both by our mitochondrial data (Figure 2) and by Lang et al. (2009). The inclusion of La. ninae in the European Lampetra clade had very good support when combining all fragments (Figure 3), and it is in agreement with Li (2014) and Tutman et al. (2017).

The genus Lampetra probably originated in the Lower Pleistocene (2.38-1.36 My; node 12 in Figure 4 and Table S1), an epoch characterized by oscillations between glacial and interglacial conditions. In glacial periods, a migratory form of Lampetra might have colonized southern rivers, whose temperatures were suitable for breeding and reproduction. Although presently Lampetra fluviatilis is restricted to western Mediterranean basins (Freyhof, 2011), it could 
have been an abundant species in the Eastern Mediterranean and Black Sea in glacial periods, when the sea and river temperatures were lower. During interglacials, the distribution of the migratory Lampetra was probably restricted to northern locations, with more favorable temperatures, similar to present day conditions. Under such environmental conditions, the non-migratory southern populations, confined to freshwater systems, isolated from other populations and with smaller population sizes, could have diverged from their migratory ancestor by genetic drift. This process might have led to the formation of these relict species, confined to southern locations.

The sister-species relationship of $C$. hellenicus and C. graecus was previously reported by Lang et al. (2009) and is confirmed here with the mitochondrial and combined datasets (Figures 2 and 3). The combined mitochondrial and nuclear analysis did not confirm their cluster with $C$. wagneri, as suggested in previous studies and our extended mitochondrial analysis. However, as it does not contradict this relation, we support the two Greek species should be placed in Caspiomyzon.

Eudontomyzon is a European monophyletic genus and diverged from Lampetra in the upper Pliocene (between 3.5 and 2.3 My; node 6 in Table S1). It is characterized by the absence of an extant anadromous species: Eudontomyzon danfordi is the trophic species of this group, but is potamodromous (Talabishka et al., 2012). The colonization patterns for this genus, assuming the absence of any other anadromous species, could have followed the evolution of the main European freshwater bodies during the Plio-Pleistocene. Our multilocus approach reveals the existence of several groups within Eudontomyzon, which seem to correspond to geographic affinities: Eu. danfordi, the predatory species, is the sister species of Eu. vladykovi which is widespread in the Danube drainage; and Eudontomyzon stankokaramani, contrary to the results in Lang et al. (2009), does not occupy a basal position in this genus, but is instead the sister group of Eu. sp., which might be an undescribed species from the Sava river. These results argue for a taxonomic revision of this genus, with emphasis on Eu. vladykovi. Also the Greek Eudontomyzon sp. Almopaios might represent an undescribed species. Its inclusion in this genus has high support (Figures 2 and 3 ). However, the specific status of this population should be further analyzed, as divergence from its sister species/population is very low (0.45\% for cytb and $0.8 \%$ for COI).

This study represents the most comprehensive work done so far on the phylogeny of European lampreys using mitochondrial and nuclear markers. Our results not only corroborate previous studies, they also raise several new pertinent questions and suggest taxonomic changes that should be addressed in the future. The inclusion of non-trophic species in this study enables us to clarify some taxonomic uncertainties, especially important when the divergence between them and their trophic species is old.

\section{ACKNOWLEDGEMENTS}

This study was funded by Fundação para a Ciencia e Tecnologia (FCT) Portugal, through the strategic projects MARE/UIDB/
MAR/04292/2020 and MARE/UIDP/MAR/04292/2020 granted to MARE (MARE-ISPA), by a grant of Russian Foundation for Basic Research, no. 19-04-00719 (Boris Levin), by the Ministry of Culture of the Czech Republic (DKRVO 2019-2023/6.IV.c National Museum, 00023272) (Radek Šanda), by institutional resources of the Ministry of Education, Youth, and Sports of the Czech Republic (Jasna Vukić), by the Czech Academy of Sciences grant no. RVO 67985904 (Lukáš Choleva), and by the SYNTHESYS Project http:// www.synthesys.info/ which is financed by European Community Research Infrastructure Action under the FP7 Integrating Activities Programme (CZ-TAF-5437). We want to thank Bella Japoshvili, Manos Koutrakis, Stamatis Zogaris, Spase Shumka, Nikola Hristovski, Antun Delić, and Ivan Bogut for their help in specimens' collection and Karen Avellaneda for her help in spanish translation.

\section{ORCID}

Ana M. Pereira (D) https://orcid.org/0000-0001-7616-4683

André Levy (D) https://orcid.org/0000-0003-4770-1886

Boris A. Levin (D) https://orcid.org/0000-0002-4044-2036

Sara M. Francisco (D) https://orcid.org/0000-0003-0907-7453

\section{REFERENCES}

Barbieri, R., Zogaris, S., Kalogianni, E., Stoumboudi, M. T., Chatzinikolaou, Y., Giakoumi, S., Kapakos, Y., Kommatas, D., Koutsikos, N., Tachos, V., Vardakas, L., \& Economou, A. N. (2015). Freshwater fishes and lampreys of Greece: An annotated checklist. Monographs on Marine Sciences No. 8. Hellenic Centre for Marine Research.

Docker, M. F. (2009). A review of the evolution of nonparasitism in lampreys and an update of the paired species concept. In L. R. Brown, S. D. Chase, M. G. Mesa, R. J. Beamish, \& P. B. Moyle (Eds.), Biology, management, and conservation of lampreys in North America (pp. 71114). American Fisheries Society. https://doi.org/10.47886/97819 34874134

Docker, M. F., Youson, J. H., Beamish, R. J., \& Devlin, R. H. (1999). Phylogeny of the lamprey genus Lampetra inferred from mitochondrial cytochrome b and ND3 gene sequences. Canadian Journal of Fisheries and Aquatic Sciences, 56, 2340-2349. https://doi. org/10.1139/f99-171

Drummond, A. J., Suchard, M. A., Xie, D., \& Rambaut, A. (2012). Bayesian phylogenetics with BEAUti and the BEAST 1.7. Molecular Biology and Evolution, 29, 1969-1973. https://doi.org/10.1093/molbev/ mss075

Felsenstein, J. (1985). Confidence-limits on phylogenies - An approach using the bootstrap. Evolution, 39, 783-791. https://doi. org $/ 10.2307 / 2408678$

Freyhof, J. (2011). Lampetra fluviatilis. (errata version published in 2016) The IUCN Red List of Threatened Species 2011: e.T11206A97805807. Downloaded on 08 February 2017.

Gess, R. W., Coates, M. I., \& Rubidge, B. S. (2006). A lamprey from the Devonian period of South Africa. Nature, 443, 981-984. https://doi. org $/ 10.1038 /$ nature05150

Gill, H. S., Renaud, C. B., Chapleau, F., Mayden, R. L., \& Potter, I. C. (2003). Phylogeny of Living Parasitic Lampreys (Petromyzontiformes) Based on Morphological Data. Copeia, 2003, 687-703. https://doi. org/10.1643/IA02-085.1

Ivanova, N.V.,Zemlak, R.H.,Hanner, R.H., \&Hebert, D. N.(2007). Universal primer cocktails for fish DNA barcoding. Molecular Ecology Notes, 7, 544-548. https://doi.org/10.1111/j.1471-8286.2007.01748.x

Krappe, M. (2004). Quantitative Analysen populationsbiologischer Phänomene im Lebenszyklus des Bachneunauges Lampetra planeri 
(Bloch 1784). Inaugural-Dissertation, Universität Rostock, (p. XXXIII $+241)$.

Kumar, S., Stecher, G., \& Tamura, K. (2016). MEGA7: Molecular evolutionary genetics analysis version 7.0 for bigger datasets. Molecular Biology and Evolution, 33, 1870-1874. https://doi.org/10.1093/ molbev/msw054

Kuraku, S., \& Kuratani, S. (2006). Time scale for cyclostome evolution inferred with a phylogenetic diagnosis of hagfish and lamprey cDNA sequences. Zoological Science, 23, 1053-1064. https://doi. org/10.2108/zsj.23.1053

Lang, N. J., Roe, K. J., Renaud, C. B., Gill, H. S., Potter, I. C., Freyhof, J., Naseka, A. M., Cochran, P., Pérez, H. E., Habit, E. M., Kuhajda B. R., Neely, D., Reshetnikov, Y. S., Salnikov, V. B., Stoumboudi, M. T., \& Mayden, R. L. (2009). Novel relationships among lampreys (Petromyzontiformes) revealed by a taxonomically comprehensive molecular data set. In L. R. Brown, S. D. Chase, M. G. Mesa, R. J. Beamish, \& P. B. Moyle (Eds.), Biology, management, and conservation of lampreys in North America (pp. 41-55). American Fisheries Society. https://doi.org/10.47886/9781934874134

$\mathrm{Li}, \mathrm{Y}$. (2014). Phylogeny of the lamprey genus Lethenteron Creaser and Hubbs 1922 and closely related genera using the mitochondrial cytochrome $b$ gene and nuclear gene introns. Master thesis, University of Manitoba.

Phillips, R. B., Sajdak, S. L., \& Domanico, M. J. (1995). Relationships among charrs based on DNA sequences. Nordic Journal of Freshwater Research, 71, 378-391.

Potter, I. C., Gill, H. S., Renaud, C. B., \& Haoucher, D. (2015). The taxonomy, phylogeny, and distribution of lampreys. In M. F. Docker (Ed.), Lampreys: Biology, conservation, and control (Vol. 1, (pp. 35-73). Fish \& Fisheries Series 37. Springer Science. https://doi. org/10.1007/978-94-017-9306-3_2

Renaud, C. B. (2011). Lampreys of the world. An annotated and illustrated catalogue of lamprey species known to date. FAO Species Catalogue for Fishery Purposes No. 5. FAO.

Riva-Rossi, C., Barrasso, D. A., Baker, C. F., Quiroga, A. P., Baigún, C., \& Basso, N. G. (2020). Revalidation of the Argentinian pouched lamprey Geotria macrostoma (Burmeister, 1868) with molecular and morphological evidence. PLoS One, 15, e0233792. https://doi. org/10.1371/journal.pone.0233792

Ronquist, F., Teslenko, M., Mark, P., Ayres, D. L., Darling, A., Höhna, S., Larget, B., Liu, L., Suchard, M. A., \& Huelsenbeck, J. P. (2012). MRBAYES 3.2: Efficient Bayesian phylogenetic inference and model selection across a large model space. Systematic Biology, 61 539-542. https://doi.org/10.1093/sysbio/sys029

Stamatakis, A., Hoover, P., \& Rougemont, J. (2008). A rapid bootstrap Algorithm for the RAxML Web-servers. Systematic Biology, 75, 758-771. https://doi.org/10.1080/10635150802429642

Swofford, D. L. (2001). PAUP*. Phylogenetic analysis using parsimony (*and Other Methods) v 4.0b10, $4 b .10$ ed. . Sinauer Associates.

Talabishka, E. M., Bogutskaya, N. G., \& Naseka, A. M. (2012). Local migration and feeding habits of Carpathian lamprey Eudontomyzon danfordi (Petromyzontes: Petromyzontidae) in Tiska river system (Danube drainage, Ukraine). Proceedings of the Zoological Institute RAS, 316, 361-368.

Tutman, P., Freyhof, J., Jakov, D., Glamuzina, B., \& Geiger, M. (2017). Lampetra soljani, a new brook lamprey from the southern Adriatic Sea basin (Petromyzontiformes: Petromyzontidae). Zootaxa, 4273 531-548. https://doi.org/10.11646/zootaxa.4273.4.4

Vladykov, V. D., \& Kott, E. (1979). Satellite species among the holarctic lampreys (Petromyzonidae). Canadian Journal of Zoology, 57, 860-867. https://doi.org/10.1139/z79-106
Ward, R. D., Zemlak, T. S., Innes, B. H., Last, P. R., \& Hebert, P. D. N. (2005). DNA barcoding Australia's fish species. Philosophical Transactions of the Royal Society of London Series B Biological Sciences, 360, 1847-1857. https://doi.org/10.1098/rstb.2005.1716

\section{SUPPORTING INFORMATION}

Additional supporting information may be found online in the Supporting Information section.

Figure S1. BA phylogenetic tree calculated with coi marker from all lampreys included in this study.

Figure S2. BA phylogenetic tree calculated with cytb marker from all lampreys included in this study.

Figure S3. BA phylogenetic tree calculated with $\mathrm{COI}$ marker from European lampreys.

Figure S4. BA phylogenetic tree calculated with cytb marker from European lampreys.

Figure S5. BA phylogenetic tree calculated with concatenated ITS-1 and ITS-2 nuclear markers from European lampreys.

Table S1. Mean node age (My) and 95\% highest posterior density (HPD) intervals estimated using mitochondrial (COI and cytb) and nuclear markers (ITS-1 and ITS-2).

Alignment S1. COI sequence alignment of European lamprey species used in BA inference.

Alignment S2. Cytb sequence alignment of European lamprey species used in BA inference.

Alignment S3. ITS-1 and ITS-2 sequence alignment of European lamprey species used in BA inference.

Alignment S4. COI sequence alignment of all lamprey species included in this study in BA inference.

Alignment S5. Cytb sequence alignment of all lamprey species included in this study in BA inference.

Alignment S6. Concatenated $\mathrm{COI}$ and $\mathrm{Cytb}$ sequences alignment of European lamprey species used in BA inference.

Alignment S7. Concatenated $\mathrm{COI}$ and $\mathrm{Cy}$ tb sequences alignment of all lamprey species included in this study in BA inference.

Alignment S8. Concatenated COI, Cytb, ITS-1 and ITS-2 sequences alignment of European lamprey species used in BA inference.

How to cite this article: Pereira, A. M., Levy, A., Vukić, J., Šanda, R., Levin, B. A., Freyhof, J., Geiger, M., Choleva, L., Francisco, S. M., \& Robalo, J. I. (2021). Putting European lampreys into perspective: A global-scale multilocus phylogeny with a proposal for a generic structure of the Petromyzontidae. Journal of Zoological Systematics and Evolutionary Research, 00, 1-12. https://doi.org/10.1111/ jzs.12522 